Pp. 1-9

DOI: 10.1089 /jamp.2016.1339

\title{
Pulmonary Drug Delivery Following Continuous Vibrating Mesh Nebulization and Inspiratory Synchronized Vibrating Mesh Nebulization During Noninvasive Ventilation in Healthy Volunteers
}

\author{
Jean-Bernard Michotte, PT, PhD, Enrico Staderini, MD, BME, PhD, \\ Anne-Sophie Aubriot, PT, MSc, Emilie Jossen, PT, BSc, Jonathan Dugernier, PT, PhD, \\ Giuseppe Liistro, MD, $\mathrm{PhD}^{6}$, and Gregory Reychler, $\mathrm{PT}, \mathrm{PhD}^{6}$
}

\begin{abstract}
Background: A breath-synchronized nebulization option that could potentially improve drug delivery during noninvasive positive pressure ventilation (NIPPV) is currently not available on single-limb circuit bilevel ventilators. The aim of this study was to compare urinary excretion of amikacin following aerosol delivery with a vibrating mesh nebulizer coupled to a single-limb circuit bilevel ventilator, using conventional continuous (Conti-Neb) and experimental inspiratory synchronized (Inspi-Neb) nebulization modes.

Materials and Methods: A crossover clinical trial involving 6 noninvasive ventilated healthy volunteers (mean age of $32.3 \pm 9.5 \mathrm{y}$ ) randomly assigned to both vibrating mesh nebulization modes was conducted: Inspi-Neb delivered aerosol during only the whole inspiratory phase, whereas Conti-Neb delivered aerosol continuously. All subjects inhaled amikacin solution $(500 \mathrm{mg} / 4 \mathrm{~mL})$ during NIPPV using a single-limb bilevel ventilator (inspiratory positive airway pressure: $12 \mathrm{~cm} \mathrm{H}_{2} \mathrm{O}$, and expiratory positive airway pressure: $5 \mathrm{~cm} \mathrm{H}_{2} \mathrm{O}$ ). Pulmonary drug delivery of amikacin following both nebulization modes was compared by urinary excretion of drug for 24 hours post-inhalation. Results: The total daily amount of amikacin excreted in the urine was significantly higher with Inspi-Neb (median: $44.72 \mathrm{mg}$; interquartile range [IQR]: 40.50-65.13) than with Conti-Neb (median: $40.07 \mathrm{mg}$; IQR: 31.00-43.73), $(p=0.02)$. The elimination rate constant of amikacin (indirect measure of the depth of drug penetration into the lungs) was significantly higher with Inspi-Neb (median: 0.137; IQR: 0.113-0.146) than with Conti-Neb (median: 0.116; IQR: 0.105-0.130), $(p=0.02)$. However, the mean pulmonary drug delivery rate, expressed as the ratio between total daily urinary amount of amikacin and nebulization time, was significantly higher with Conti-Neb $(2.03 \mathrm{mg} / \mathrm{min})$ than with Inspi-Neb $(1.09 \mathrm{mg} / \mathrm{min})(p<0.01)$.

Conclusions: During NIPPV with a single-limb circuit bilevel ventilator, the use of inspiratory synchronized vibrating mesh nebulization may improve pulmonary drug delivery compared with conventional continuous vibrating mesh nebulization.

Keywords: aerosol delivery, amikacin, bilevel ventilator, breath-synchronized nebulizer, healthy volunteers, nebulization, nebulization mode, noninvasive positive pressure ventilation, pulmonary drug delivery, single-limb circuit ventilator, vibrating mesh nebulizer

\footnotetext{
${ }^{1}$ Western Switzerland University of Applied Sciences-Haute Ecole de Santé Vaud (HESAV), Filière Physiothérapie, 1011 Lausanne, Switzerland.

${ }^{2}$ Western Switzerland University of Applied Sciences-Haute Ecole d'Ingénierie et de Gestion du Canton de Vaud (HEIG-VD), 1401 Yverdon-les-Bains, Switzerland.

${ }^{3}$ Cliniques Universitaires Saint-Luc, Centre de Référence pour la Mucoviscidose, 1200 Brussels, Belgium.

${ }^{4}$ Ligue pulmonaire neuchâteloise, 2034 Peseux, Switzerland.

${ }^{5}$ Cliniques Universitaires Saint-Luc, Service des soins intensifs, 1200 Brussels, Belgium.

${ }^{6}$ Cliniques Universitaires Saint-Luc, Service de Pneumologie; Université Catholique de Louvain, Institut de Recherche Expérimentale et Clinique (IREC), Pôle de Pneumologie, ORL \& Dermatologie, 1200 Brussels, Belgium.
} 


\section{Introduction}

A EROSOL DELIVERY DURING NONINVASIVE POSITIVE PRESSURE VENTILATION (NIPPV) has been little studied in human clinical trials, other than a few studies focusing specifically on the pulmonary delivery of drugs. ${ }^{(1-4)}$ Some clinical benefits have been reported in small trials ${ }^{(5-8)}$; however, the evidence is not sufficiently robust to recommend routine use of NIPPV for aerosol therapy. ${ }^{(3)}$ The effectiveness of nebulization is related to the mass of drug deposited in the lungs. ${ }^{(9-11)}$ During NIPPV, the fraction of the nominal dose actually administered depends on many factors, including the nebulizer device $^{(4,12,13)}$ and its position in the ventilator circuit. ${ }^{(3,12-15)}$

Recently, some technical issues regarding drug nebulization during NIPPV using a single-limb circuit bilevel ventilator were investigated and resolved with the help of bench studies. ${ }^{(12,14,16-18)}$ These studies concluded that the optimal position of the nebulizer device was between the patient and the passive exhalation port. ${ }^{(3,12,14,15,18)}$ Moreover, they showed that vibrating mesh nebulizer devices were more efficient than jet nebulizer devices. ${ }^{(12,13,18)}$

Although the use of breath-synchronized nebulizers could potentially improve aerosol delivery during NIPPV, ${ }^{(19-21)}$ this technical aspect has been little studied because breathsynchronized nebulizers are currently not commercially available for use with bilevel ventilators. ${ }^{(3)}$ In a previous bench study, ${ }^{(21)}$ we showed that the respirable dose of amikacin from a vibrating mesh nebulizer coupled to a singlelimb circuit bilevel ventilator could be increased by the use of an inspiratory synchronized nebulization mode, instead of the conventional continuous nebulization mode. However, due to the complexity of human airways, ${ }^{(22)}$ the influence of ventilator-related factors (e.g., interface and settings), ${ }^{(15,23-25)}$ and patient-related factors (e.g., tidal volume, respiratory rate, and inspiratory time) ${ }^{(15,17)}$ a human clinical study is required to confirm the findings of our in vitro study. ${ }^{(3)}$

Monitoring the urinary excretion of a drug for 24 hours post-inhalation has been validated as a method to estimate the lung delivery of drugs ${ }^{(26-28)}$ as well as to compare different nebulizer devices in patients under mechanical ventilation. ${ }^{(27,29-31)}$

On the basis of our previous in vitro study, ${ }^{(21)}$ we hypothesized that an inspiratory synchronized vibrating mesh nebulization mode would enhance aerosol drug delivery to the lungs of noninvasive ventilated patients, compared with a conventional continuous vibrating mesh nebulization mode. Therefore, the main aim of this study was to compare the urinary excretion of amikacin for 24 hours, following nebulization with a vibrating mesh device operating (1) in an inspiratory synchronized mode and (2) in the conventional continuous mode, in adult healthy volunteers undergoing NIPPV with a single-limb circuit bilevel ventilator. We also analyzed the pulmonary drug delivery rate, expressed as the ratio between total daily urinary amount of amikacin and nebulization time, and the elimination rate constant of amikacin, as an indirect measure of the depth of drug penetration into the lungs.

\section{Materials and Methods}

\section{Subjects}

After approval by the Ethics Committee of our institution (Comité d'Ethique Hospitalo-Facultaire, Université Cath- olique de Louvain; Registration number: B403201524418), we recruited six non-smoking healthy male volunteers who gave their written informed consent after receiving complete protocol information (Clinical Trials: NCT01901497). Inclusion criteria included age between 18 and 65 years and no history of cardiovascular or lung diseases. Exclusion criteria included abnormal renal function, treatment with aminoglycosides within the previous 3 months, allergy to aminoglycosides, and inability to tolerate NIPPV. Each volunteer performed a spirometry test according to the American Thoracic Society/ European Respiratory Society (ATS/ERS) guidelines. ${ }^{(32)}$ Subjects were excluded if forced vital capacity $(\mathrm{FVC})$ and forced expiratory volume in 1 second $\left(\mathrm{FEV}_{1}\right)$ were $<80 \%$ of the predicted value or they were unable to tolerate NIPPV.

\section{Experimental aerosol delivery system and bilevel ventilator}

As previously described in our bench study, ${ }^{(21)}$ we used an experimental aerosol delivery system, including an Aerogen ${ }^{\circledR}$ Solo vibrating mesh nebulizer powered by the Aerogen Pro Controller (Aerogen Ltd.; Dangan, Galway, Ireland), a prototype control module called Synchro-Neb (HEIG-VD and HESAV, Yverdon-les-Bains, Switzerland), and a pressure sensor (Honeywell Sensing and Control; model SSCSANN005PGAA5, Minneapolis, MN) connected to the outlet of the bilevel ventilator (between the circuit and the ventilator) through a T-piece adapter (Fig. 1).

The Synchro-Neb was developed to synchronize nebulization with the whole inspiratory phase of the bilevel ventilator. Based on an electrical signal from the pressure sensor, the control module detects a minimal positive or negative variation of pressure of $4 \mathrm{cmH}_{2} \mathrm{O}$ (above expiratory positive airway pressure [EPAP]) in the ventilator circuit (InspiratoryExpiratory and Expiratory-Inspiratory cyclings) and switches on/off the Aerogen Pro Controller and hence the nebulizer device. In previous tests, a 20-milisecond delay has been measured between the onset of insufflation and the actuation of nebulization and between the end of insufflation and the interruption of nebulization (unpublished data). Moreover, SynchroNeb has been found to respond perfectly to simulated breathing rates exceeding 45 breaths per minute (unpublished data).

Similarly to our in vitro study, ${ }^{(21)}$ we tested two different nebulization modes:

- Continuous nebulization mode (Conti-Neb), with the nebulizer operating continuously, irrespective of the inspiratory and exhalation phases (conventional mode).

- Inspiratory synchronized nebulization mode (Inspi$\mathrm{Neb}$ ), in which the nebulizer operated only during the whole inspiratory phase (experimental mode).

The experimental aerosol delivery system was coupled to a Philips Trilogy ${ }^{\circledR} 100$ (Philips Respironics, Murrysville, PA) bilevel ventilator used with an adult single-limb circuit $(180 \mathrm{~cm}$ length $\times 22 \mathrm{~mm}$ diameter), a passive exhalation port (Whisper Swivel II ${ }^{\circledR}$; Philips-Respironics, Murrysville, PA), and a facial mask (Vygon ${ }^{\circledR}$ Schweiz GmbH, Niederwangen BE, Schweiz). No heating or humidification systems were used.

\section{Study design}

This double-blind, randomized crossover study was performed in the Department of Intensive Care and the 


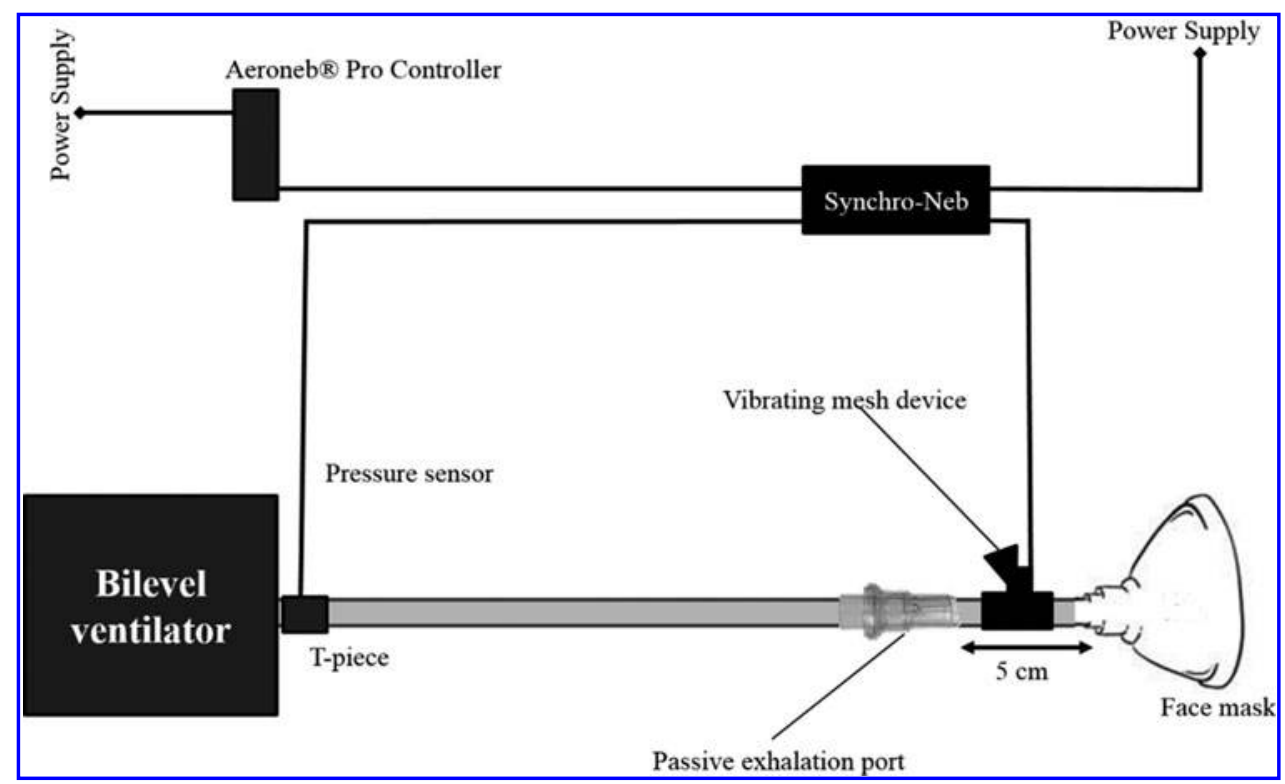

FIG. 1. Schematic showing our setup for nebulization during noninvasive ventilation. The experimental aerosol delivery system connected to a single-limb circuit bilevel ventilator.

Department of Pneumology at Saint-Luc University Hospital, Brussels, Belgium. All subjects were recruited by local advertisement. A schematic representation of the present study is illustrated in Figure 2.

Before beginning the experiment, all volunteers were fitted with the facial mask and trained to use the NIPPV. Computer software (www.randomizer.org/) was used to randomize the order of the nebulizer trials. Conti-Neb or Inspi-Neb was coupled to a bilevel ventilator set in spontaneous mode, with fixed levels of inspiratory positive airway pressure (IPAP) of $12 \mathrm{cmH}_{2} \mathrm{O}$ and EPAP of $5 \mathrm{cmH}_{2} \mathrm{O}$, a flow trigger sensitivity of $9 \mathrm{~L} / \mathrm{min}$, an inspiratory cycle-off of $25 \%$, and an inspiratory rise time set at level 3 (fastest response $=1$ and slowest response $=6$ ). These levels of IPAP and EPAP were already used in two previous studies. ${ }^{(4,33)}$

A washout period of 1 week between the two trials was respected for each subject. This period allows eliminating all residual drug due to its short half-life. ${ }^{(27,34)}$ Each trial was carried out in the same room at an ambient temperature (mean $\left.=23.8^{\circ} \mathrm{C} \pm 1.7\right)$ and at the same time of the day (2 p.m). All volunteers acted as their own controls, thus reducing the amount of error arising from anatomical (e.g., airway morphology and nasal-laryngeal airway volumes) and mechanical (e.g., airway resistance) differences between individuals. $^{(34,35)}$

The nebulizer device was connected to the ventilator circuit with specific adapters (recommended by the manufacturer) positioned between the face mask and the passive exhalation port. The device was filled with $500 \mathrm{mg}$ of amikacin (Amukin, Bristol-Myers Squibb, Braine-l'Alleud, Belgium) diluted in $4 \mathrm{~mL}$ of normal saline solution.

For each subject, a new nebulizer device and complete ventilator circuit, including the facial mask and passive exhalation port, were used. The specific adapters were cleaned, disinfected, and dried after each test according to the manufacturer's instructions.

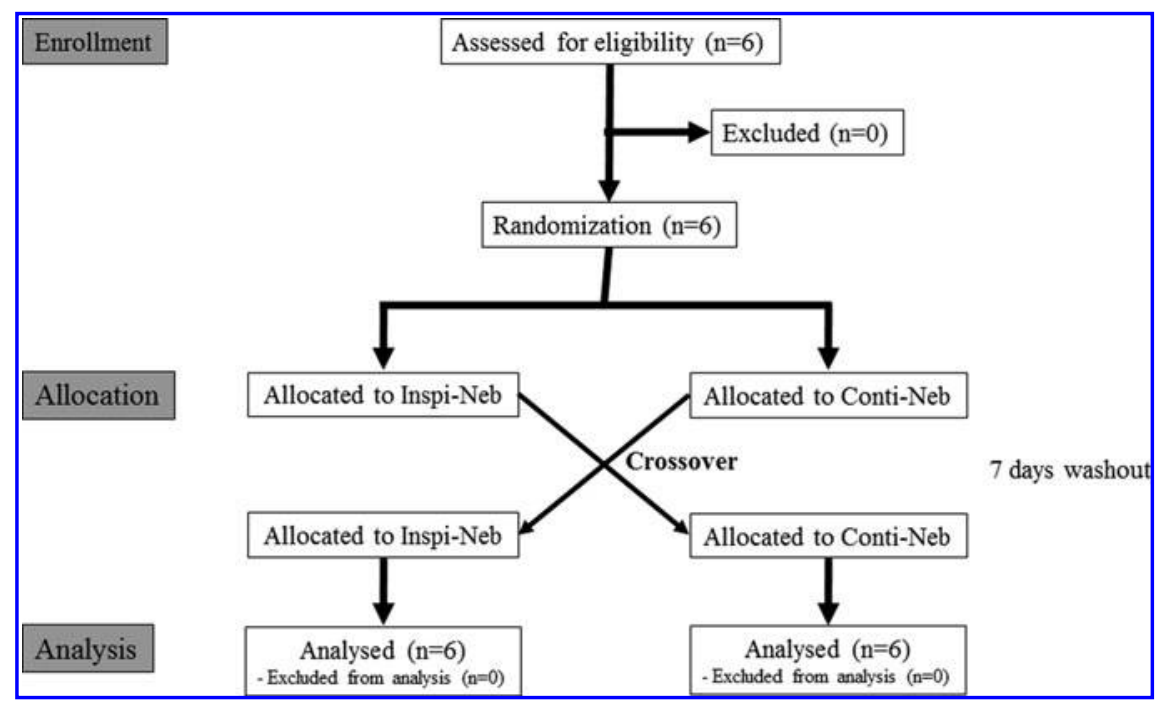

FIG. 2. Flow diagram of the study. 
During NIPPV, the subjects were seated comfortably and breathed spontaneously through the facial mask secured with standard headgear and straps. The facial mask was adjusted until the participant felt comfortable and there was no leak from the interface between the face and mask. All volunteers were encouraged to breathe normally through the mouth. Nebulization was started 5 minutes after the bilevel ventilator to allow the subjects to acclimatize to the ventilator and their breathing pattern to stabilize. Nebulization was considered to be finished when no aerosol cloud was visible for a period of 30 seconds. The bilevel ventilator was switched off 1 minute after the end of the nebulization time.

All experiments were performed by three investigators (J.B.M., A.S.A., and E.J.). In this double-blind trial, the enrolled subjects were assigned by the investigator J.B.M. The total daily amount of amikacin excreted in the urine was assessed by the investigator A.S.A. who was blinded to the nebulization mode. The investigator E.J. and subjects were blinded to the nebulization mode used in each session and results obtained.

\section{Measurements}

During both nebulization sessions, the respiratory rate, total leaks, tidal volume, minute ventilation, inspiratory flow, and $\mathrm{Ti} / \mathrm{Tt}$ tot ratio monitored by the bilevel ventilator were recorded and analyzed with DirectView v1.3 ventilation data management software (Philips Respironics, Murrysville, PA).

Just before the experiments, the volunteers were requested to empty their bladder and to collect the first urine sample. Then, urine samples were collected at each micturition for 24 hours after nebulization. The precise volume and exact time of the micturition were recorded. The concentration of amikacin in each sample was measured using the fluorescence polarization immunoassay method (Abbott Laboratories, Abbott Park, IL).

The primary outcome was the total daily amount of amikacin excreted in the urine $(\mathrm{Cu} \max )$, reflecting pulmonary drug delivery. ${ }^{(26-28)}$ This outcome was calculated by summing the amount of amikacin measured at each micturition. The $\mathrm{Cu}$ max was expressed in absolute values (mg) or as a percentage of the nominal dose of amikacin (\%). Secondary outcomes included the constant of elimination $(\mathrm{Ke})$ and the duration of nebulization. Ke was calculated by fitting the curve of the cumulated amount of amikacin excreted in urine plotted over time. The elimination kinetics of amikacin is dose dependent. As the urine level increases, the value of Ke increases. Ke can be taken as an indirect measure of depth to which drugs penetrate into the lung. ${ }^{(27,36)}$ The duration of nebulization, defined as the time from the beginning of nebulization (nebulizer turned on) until the end of aerosol production (no aerosol cloud), was also recorded for each nebulization mode. It was measured by the same investigator using a stopwatch.

\section{Statistics}

Results are presented as mean \pm standard deviation with 95\% confidence intervals or median with interquartile ranges (IQRs) depending on their distribution. Without any previous clinical studies that have used the same method of analysis, the sample size calculation was based on an estimated minimal clinically relevant difference of $10 \% .{ }^{(37)}$ To detect such a difference in total daily amount of urinary amikacin excretion at a 5\% significance level for a twosided test with a statistical power of $80 \%$, the sample size needed was five subjects $(n=5)$.

Differences between the two nebulization modes were assessed using a paired Student's $t$-test or Wilcoxon signedrank test in case of non-normality distribution according to Kolmogorov-Smirnov tests. A difference was considered statistically significant when the $p$-value was less than 0.05 . Statistical analysis was performed with the commercially available software Stata (Stata/IC 12.1 for Windows; StataCorp LP, Texas).

\section{Results \\ Patients}

Six healthy volunteers were assessed for eligibility and none were excluded. Mean anthropometric parameters and pulmonary function tests of the six healthy volunteers are presented in Table 1. They all had normal lung function $\left(\mathrm{FVC}=102.8 \% \pm 8.8 \%\right.$ predicted $; \mathrm{FEV}_{1}=99.5 \% \pm 10.1 \%$ predicted).

\section{Respiratory monitoring}

No significant differences were found between tidal volume [1351.4 mL (IQR: $1194.8-1436.5$ ) vs. $1324.5 \mathrm{~mL}$ (IQR: 1276.3-1534.1) for Inspi-Neb and Conti-Neb, respectively, $p=0.60]$, respiratory rate $[12.1$ breath/minute (IQR: $10.4-$ $14.3)$ vs. 12.5 (11.6-14.4) breath/minute for Inspi-Neb and Conti-Neb, respectively, $p=0.60]$, minute volume [16.2

Table 1. Anthropometric and Pulmonary Function Data of Six Volunteers

\begin{tabular}{lcccccc}
\hline Subject & $\begin{array}{c}\text { Age } \\
\text { (years) }\end{array}$ & $\begin{array}{c}B M I \\
\left(\mathrm{~kg} / \mathrm{m}^{2}\right)\end{array}$ & $\begin{array}{c}F E V_{l} \\
\text { (\% predicted })\end{array}$ & $\begin{array}{c}F V C \\
\text { (\% predicted) }\end{array}$ & $\begin{array}{c}F E V_{1} / F V C \\
\text { (\% predicted })\end{array}$ & $\begin{array}{c}P E F \\
(\mathrm{~L} / \mathrm{min})\end{array}$ \\
\hline 1 & 23 & 27.2 & 89 & 92 & 87 & 624 \\
2 & 47 & 23.9 & 113 & 116 & 100 & 826 \\
3 & 28 & 25.5 & 91 & 99 & 94 & 533 \\
4 & 32 & 26.3 & 92 & 97 & 85 & 585 \\
5 & 24 & 26.0 & 105 & 110 & 96 & 726 \\
6 & 40 & 24.8 & 107 & 103 & 93.8 & 657.7 \\
Mean & 32.3 & 25.6 & 99.5 & 8.8 & 5.9 & 104.9 \\
SD & 9.5 & 1.2 & 10.1 & & & \\
\hline
\end{tabular}

BMI, body-mass index; $\mathrm{FEV}_{1}$, forced expiratory volume in 1 second; FVC, forced vital capacity; $\mathrm{FEV}_{1} / \mathrm{FVC}$, Tiffeneau index; PEF, peak expiratory flow. 
L/min (IQR: 15.2-17.4) vs. $16.7 \mathrm{~L} / \mathrm{min}$ (IQR: 13.0-20.5) for Inspi-Neb and Conti-Neb, respectively, $p=0.60$ ], and Ti/ Ttot ratio [0.36 (IQR: 0.34-0.41) vs. 0.37 (IQR: 0.36-0.39) for Inspi-Neb and Conti-Neb, respectively, $p=0.91]$ measured during each type of nebulization.

\section{Nebulization monitoring}

The duration of nebulization was influenced by the nebulization mode. It was significantly longer with Inspi-Neb than with Conti-Neb [median: 46.25 minutes (IQR: 43.1548.15) vs. 18.35 minutes (IQR: 17.80-22.10) for Inspi-Neb and Conti-Neb, respectively; $p=0.01]$.

\section{Drug monitoring}

The total daily amount of amikacin excreted in the urine was influenced by the nebulization mode. It was significantly higher with Inspi-Neb than with Conti-Neb [median: $44.72 \mathrm{mg}$ (IQR: $40.50-65.13)$ vs. $40.07 \mathrm{mg}$ (IQR: $31.00-43.73$ ) for Inspi-Neb and Conti-Neb, respectively; $p=0.02]$. In addition, the elimination rate constant of amikacin was significantly higher with Inspi-Neb than with Conti-Neb [median: 0.137 (IQR: 0.113-0.146) vs. 0.116 (IQR: 0.105-0.130) for InspiNeb and Conti-Neb, respectively; $p=0.02]$.

\section{Discussion}

The purpose of this randomized crossover study was to compare the lung delivery of amikacin with inspiratory synchronized and continuous vibrating mesh nebulization in healthy volunteers undergoing NIPPV with a single-limb circuit bilevel ventilator. We found (1) higher urinary excretion of amikacin, (2) a greater constant of elimination of amikacin, and (3) a longer nebulization time with inspiratory synchronized nebulization (Inspi-Neb) than with continuous nebulization (Conti-Neb).

The higher level of effectiveness of breath-actuated nebulization has already been reported in intubated and mechanically ventilated patients. ${ }^{(38,39)}$ In a clinical study involving patients undergoing treatment with antibiotics, Miller et al. ${ }^{(39)}$ showed that when a breath-actuated jet nebulizer is used, instead of a continuous operating jet nebulizer, the delivered dose increases by more than five times. However, it is difficult to extrapolate these results to subjects on NIPPV using a single-limb circuit bilevel ventilator. Indeed, in our present study, urinary excretion of amikacin with synchronized nebulization was $\sim 1.30$ times greater than with continuous nebulization.

This low difference between continuous and synchronized nebulization regarding the previous articles in mechanical ventilation could be explained by several factors related to our experimental aerosol delivery system: (1) The use of a vibrating mesh device normally designed to operate continuously. The intermittent operating of our device associated with the high viscosity of amikacin could have affected its performance (e.g., particle size distribution and residual volume) and led to a decrease in aerosol delivery with Inspi-Neb. ${ }^{(21,40,41)}$ (2) The delay of 20 milliseconds measured between the beginning of insufflation and actuation of our nebulizer (unpublished data) could have released the drug late in the inspiratory phase of subjects. The time for the nebulized drug to reach the lungs before the onset of exhalation could have been too short, especially in subjects with low Ti/Ttot. ${ }^{(12,21,42)}$ Therefore, a higher amount of drug might have been delivered to the oropharynx ${ }^{(43)}$ and lost in the circuit (including the face mask), ${ }^{(21)}$ thereby reducing the deep pulmonary delivery (e.g., alveolar spaces) with Inspi-Neb. ${ }^{(12,21,42,44)}$

(3) The delay of 20 milliseconds measured between the end of insufflation and the stop actuation of the nebulizer (unpublished data) could have increased the amount of drug lost during exhalation. This delay could have increased total lost dose, and thus decreased aerosol delivery with InspiNeb. ${ }^{(44,45)}$ (4) The ventilation techniques such as the use of ventilator with single-limb circuit, face mask, and ventilator settings could have promoted a large reservoir effect with Conti-Neb. ${ }^{(16,46)}$ A large amount of drug nebulized during the expiratory phase could have been stored in the circuit (including the face mask) and delivered during the next inspiratory phase, thereby improving aerosol delivery with Conti-Neb, ${ }^{(16,21,42,44)}$ and hence its difference in pulmonary drug with Inspi-Neb.

Other than in the study by Galindo-Filho et al., ${ }^{(4)}$ the vibrating mesh nebulizer coupled to a bilevel ventilator has never been tested in clinical studies. In a crossover study assessing radioaerosol pulmonary deposition in noninvasive ventilated healthy subjects, the authors showed that the vibrating mesh nebulizer delivered up to twice more radioaerosol particles into the respiratory tract than the jet nebulizer device.

To our knowledge, our study is the first clinical study to investigate the use of inspiratory synchronized vibrating mesh nebulization in subjects undergoing NIPPV with single-limb circuit bilevel ventilators. ${ }^{(2,3)}$ The present results confirmed the findings of our previous bench study, ${ }^{(21)}$ where inspiratory synchronized vibrating mesh nebulization, during NIPPV with single-limb circuit bilevel ventilators, significantly enhanced pulmonary delivery compared with continuous vibrating mesh nebulization. The higher urinary excretion with Inspi-Neb (on average $21 \%$ more than with Conti-Neb) may be mainly explained by the fact that aerosol loss through the passive exhalation port is minimized during expiratory time (unlike Conti-Neb), because the nebulizer only operates during the total inspiratory time, therefore increasing the dose of medication available to the patient. (12,13,39,45) $^{-1}$

In our previous bench study ${ }^{(21)}$ that compared both nebulization modes during NIPPV with different respiratory conditions (respiratory rate, resistance, and Ti/Ttot), we showed that the total lost dose (including drug lost through the passive exhalation port and in the circuit) was significantly reduced (up to $35 \%$ of the nominal dose), and the respirable dose was significantly increased (up to $32 \%$ of the nominal dose) with Inspi-Neb compared with Conti-Neb. Although our current results were quite well predicted by our previous bench study, ${ }^{(21)}$ it is difficult to match pulmonary drug delivery evaluated, by the total daily urinary amount of drug, with the respirable dose measured in vitro. ${ }^{(29)}$ The difference between the results of the total daily urinary amount of drug and the respirable dose could be partly explained by two factors.

First, unlike the respirable dose measured at the outlet of the ventilator circuit, pulmonary drug delivery was influenced by the face mask, and by anatomical and mechanical characteristics of the subject's airways. ${ }^{(29)}$ Second, the breathing patterns of healthy volunteers likely differed from 


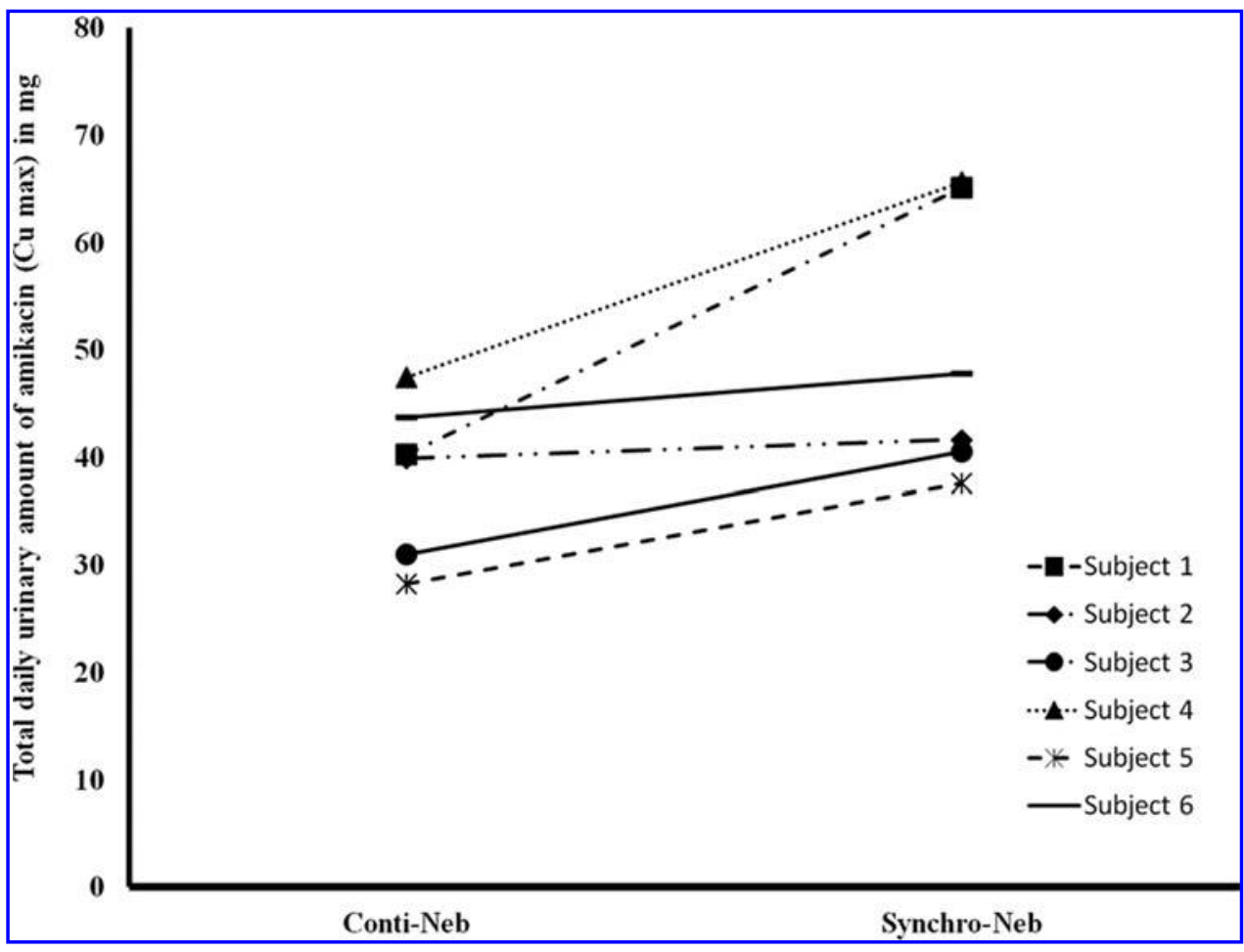

FIG. 3. Individual data of total daily urinary amount of amikacin (CU max) obtained with Conti-Neb and Synchro-Neb showing the difference of interindividual variability.

the respiratory parameters set in our bench model (e.g., tidal volume, respiratory rate, and inspiratory time) and could have influenced the lung dose delivered with Conti-Neb. ${ }^{6,14,16,17,24)}$

The increasing of total daily urinary amount of amikacin showed high intersubject variability (Fig. 3). The high increasing for subjects 1 and 4, and low increasing for subjects 2 and 6 may be explained by two factors. First, the larger minute ventilation and the longer expiratory time measured in subjects 1 and 4, compared with subjects 2 and 6 , may have led to an increasing amount of drug lost through the passive exhalation port ${ }^{(12,14,18,21)}$ and in the circuit. ${ }^{(16,17,21)}$

Therefore, the impact of Inspi-Neb, which only operates during the whole inspiratory time, may have been more important, thereby increasing the difference in total daily urinary amount of amikacin. Second, although all subjects were encouraged to breathe through the mouth, we noticed that subjects 2 and 6 were often breathing through the nose during the Inspi-Neb session. Nasal breathing may have affected aerosol deposition in the lungs, ${ }^{(47)}$ and thus reduced the impact of Inspi-Neb and the difference in total daily urinary amount of amikacin.

The size distribution of aerosol particles is a critical determinant of depth of penetration into the lung. ${ }^{(11,12,23,29,39,48)}$ We used the constant of elimination as an indirect measure of the depth of penetration of the drug into the lungs. ${ }^{27,36)}$ Our results showed that the constant of elimination was significantly higher with Inspi-Neb than with Conti-Neb, suggesting lung deposition of amikacin in more peripheral lung regions (without any other precision on these localizations) when using Inspi-Neb. We hypothesize that this difference might be due to differences in the composition of the aerosol cloud produced at the outlet of the ventilator circuit during nebulization. ${ }^{(41)}$
During Conti-Neb, the aerosol cloud delivered to the lungs resulted in a mixing of the particles produced during the ongoing inspiratory phase with the particles left in the circuit from the preceding expiratory phase. ${ }^{(12,16)}$ In contrast, during Inspi-Neb, the particles came primarily from the ongoing inspiration phase. In our previous in vitro study, ${ }^{(21)}$ we showed that the volume median diameter (i.e., the particle diameter at which $50 \%$ of the volume of the aerosol particles are larger and $50 \%$ are smaller) of the particles in the aerosol cloud at the outlet of the ventilator circuit was significantly smaller during Inspi-Neb than during Conti-Neb. Therefore, the size distribution of aerosol particles, produced by Inspi-Neb during NIPPV, could have promoted deeper lung penetration than ContiNeb. Moreover, the greater lung delivery with Inspi-Neb might also have contributed to the increased rate of elimination. $^{(49)}$

The use of inspiratory synchronized nebulization mode may significantly increase treatment time in mechanically ventilated patients. ${ }^{(50,51)}$ In the present study, Inspi-Neb required on average 2.5 times longer time than Conti-Neb to nebulize the same nominal dose of amikacin $(500 \mathrm{mg} / 4 \mathrm{~mL})$, but produced a lung dose $\sim 21 \%$ greater. Pulmonary drug delivery rate, expressed as the ratio between the total daily urinary amount of amikacin and the nebulization time, was on average 1.86 times significantly higher with Conti-Neb $(2.03 \mathrm{mg} / \mathrm{min})$ than with Inspi-Neb $(1.09 \mathrm{mg} / \mathrm{min})$.

This point raises the question whether Inspi-Neb may be useful in clinical situations in which rapid clinical responses with low lung doses are needed (e.g., $\beta 2$-agonist), particularly for the management of noninvasive ventilated patients with acute exacerbations of their condition (e.g., asthma or COPD). Studies in mechanically ventilated patients showed 
that a significant bronchodilator response occurs after nebulization of $2.5 \mathrm{mg}$ of albuterol. ${ }^{(24,52)}$

In addition, they observed that the delivery of higher doses produced a minimal therapeutic advantage and, moreover, the potential for side effects was increased. ${ }^{(23,24,53)}$ The use of Inspi-Neb would be more appropriate in clinical situations involving nebulization of expensive or toxic drugs, or when the dose of drug delivered is critical (e.g., antibiotics in ventilated patients with cystic fibrosis $(\mathrm{CF})) .{ }^{(6,50)}$ For the administration of quick relief or rescue medications, such as $\beta 2$-agonists in patients in a phase of exacerbation, the subjects of further research studies should be the development of specific synchronized nebulizers (for use in noninvasive ventilation) with high mass output and short reaction time.

Some limitations should be considered when interpreting the results of this study.

First, we used an experimental aerosol delivery system based on a vibrating mesh nebulizer normally designed to operate continuously. The intermittent operating mode of the nebulizer may have modified its behavior (e.g., vibration frequency of the device) and its performances (e.g., particle size distribution and residual volume). ${ }^{(21,41)}$ Moreover, a delay of 20 milliseconds has been measured between the onset of insufflation and actuation of the nebulizer, and between the end of insufflation and stop actuation of the nebulizer (unpublished data). The results observed with InspiNeb may be different with another synchronization system.

Second, aerosol delivery may be affected by several factors, including the structure and mechanical properties of patients' airways ${ }^{(29,54,55)}$ respiratory parameters, and ventilator settings. ${ }^{(14,17,27)}$ However, since a within-subject design was used to compare nebulization modes, with the same ventilator settings for each mode and no significant differences found in the breathing patterns, the influence of these factors was minimized. Further investigations with patients with different pulmonary diseases (e.g., COPD and cystic fibrosis), physiological parameters, and ventilator settings are needed to extrapolate the present results to other conditions.

Third, we evaluated pulmonary drug delivery in healthy volunteers limiting the ability to demonstrate a differential response to various respiratory patterns and inhaled medications. Information regarding the pharmacological response of patients with pulmonary diseases can, therefore, not reliably be derived from these data. Further clinical studies with patients are warranted to establish whether these results are clinically relevant.

Fourth, we did not use a humidifier in our study because it is an important factor affecting aerosol delivery. The heat and moisture exchanger acts as a physical barrier to aerosol delivery, therefore it should be removed before drug nebulization. ${ }^{(23)}$ Although switching off the heated humidifier is not recommended for routine aerosol therapy (e.g., bronchodilators), ${ }^{(23,56,57)}$ suspending humidification could be indicated during nebulization of expensive drugs (e.g., antibiotics $)^{(23,56)}$ because of the hygroscopic effects of humidification. ${ }^{(23)}$ However, the effects of switching off the heated humidifier before administration of aerosol are difficult to predict, ${ }^{(46)}$ especially in long-term NIPPV patients where it enhances comfort and tolerance. ${ }^{(58,59)}$ Indeed, it has been shown that after 3 hours of humidifier operation, turning off the heated humidifier for up to 30 minutes before aerosol therapy did not improve drug delivery. ${ }^{(46)}$ Therefore, the results of our study may not be extrapolated to NIPPV with a heated humidifier even if it is turning off before administration of aerosol.

Fifth, aerosol delivery may be affected by properties of the drug solution ${ }^{(40,60)}$ and brand of the vibrating mesh device. $^{(18)}$ Moreover, the reliability of reusable vibrating mesh nebulizers may be decreased with repeated use over time. ${ }^{(18,61)}$ The results may not be applied to the same nebulizer used with other medications or to other brands of vibrating mesh nebulizers or reusable devices.

Sixth, even if subjects were encouraged to breathe through the mouth with a face mask, it cannot be excluded that amikacin concentration may be influenced by nasal drug deposition. However, amikacin diffusion from the nasal cavities to the blood is affected by a large number of factors, such as the physicochemical properties of nasal mucus (low permeability to cationic drugs, such as aminoglycosides $),{ }^{(62,63)}$ the nasal epithelium structure (mainly ciliated pseudostratified columnar epithelium hindering nasal drug diffusion), ${ }^{(64)}$ and the nasal mucociliary clearance rate (high mucociliary clearance rate shortening nasal residential time of drugs and thus limiting diffusion of drug). ${ }^{(65,66)}$ The results of our study may not be extrapolated to NIPPV using nasal masks.

In conclusion, during NIPPV with a single-limb circuit bilevel ventilator, the use of inspiratory synchronized vibrating mesh nebulization may improve pulmonary drug delivery compared with conventional continuous vibrating mesh nebulization. Therefore, the development and commercial availability of breath-actuated nebulizer systems should be considered for bilevel ventilators to reduce aerosol loss and ensure optimal aerosol delivery, especially for nebulization of expensive or toxic drugs. However, clinical trials in patients with pulmonary diseases are required to determine if these results are clinically relevant.

\section{Acknowledgments}

The authors extend their special thanks to Françoise Van Bambeke, Pharm, PhD, and Giulio Muccioli, Pharm, PhD, for their advice and suggestions in the early phase of the thesis, particularly in writing this article. They also wish to thank Zélie Degiacomi and Liya Croix-Dousse for revising the manuscript.

\section{Author Disclosure Statement}

The authors declare that no competing financial interests exist.

\section{References}

1. Ehrmann S, Roche-Campo F, Bodet-Contentin L, Razazi K, Dugernier J, Trenado-Alvarez J, Donzeau A, Vermeulen F, Thevoz D, Papanikolaou M, Edelson A, Leon Yoshido H, Piquilloud L, Lakhal K, Lopes C, Vicent C, Desachy A, Apiou-Sbirlea G, Isabey D, Brochard L, Reva Research Network; AT@ICU Study Group: Aerosol therapy in intensive and intermediate care units: Prospective observation of 2808 critically ill patients. Intensive Care Med. 2016;42:192-201.

2. Guerin C, Fassier T, Bayle F, Lemasson S, and Richard JC: Inhaled bronchodilator administration during mechanical ventilation: How to optimize it, and for which clinical benefit? J Aerosol Med Pulm Drug Deliv. 2008;21:85-96. 
3. Hess DR: Aerosol therapy during noninvasive ventilation or high-flow nasal cannula. Respir Care. 2015;60:880-891; discussion 891-883.

4. Galindo-Filho VC, Ramos ME, Rattes CS, Barbosa AK, Brandao DC, Brandao SC, Fink JB, and de Andrade AD: Radioaerosol pulmonary deposition using mesh and jet nebulizers during noninvasive ventilation in healthy subjects. Respir Care. 2015;60:1238-1246.

5. Brandao DC, Lima VM, Filho VG, Silva TS, Campos TF, Dean E, and de Andrade AD: Reversal of bronchial obstruction with bi-level positive airway pressure and nebulization in patients with acute asthma. J Asthma. 2009;46: 356-361.

6. Fauroux B, Itti E, Pigeot J, Isabey D, Meignan M, Ferry G, Lofaso F, Willemot JM, Clement A, and Harf A: Optimization of aerosol deposition by pressure support in children with cystic fibrosis: An experimental and clinical study. Am J Respir Crit Care Med. 2000;162:2265-2271.

7. Galindo-Filho VC, Brandao DC, Ferreira Rde C, Menezes MJ, Almeida-Filho P, Parreira VF, Silva TN, RodriguesMachado Mda G, Dean E, and Dornelas de Andrade A: Noninvasive ventilation coupled with nebulization during asthma crises: A randomized controlled trial. Respir Care. 2013;58:241-249.

8. Maccari JG, Teixeira C, Savi A, de Oliveira RP, Machado AS, Tonietto TF, Ludwig E, Teixeira PJ, and Knorst MM: Nebulization during spontaneous breathing, CPAP, and bilevel positive-pressure ventilation: A randomized analysis of pulmonary radioaerosol deposition. Respir Care. 2014;59: 479-484.

9. Chatburn RL, and McPeck M: A new system for understanding nebulizer performance. Respir Care. 2007;52: 1037-1050.

10. Dhand R: New frontiers in aerosol delivery during mechanical ventilation. Respir Care. 2004;49:666-677.

11. Harvey CJ, O'Doherty MJ, Page CJ, Thomas SH, Nunan TO, and Treacher DF: Comparison of jet and ultrasonic nebulizer pulmonary aerosol deposition during mechanical ventilation. Eur Respir J. 1997;10:905-909.

12. Abdelrahim ME, Plant $\mathrm{P}$, and Chrystyn H: In-vitro characterisation of the nebulised dose during non-invasive ventilation. J Pharm Pharmacol. 2010;62:966-972.

13. McPeck M: Improved aerosol drug delivery with an electronic mesh nebulizer during non-invasive ventilation. (Abstract) Presented at the Amercican Thoracic Society 2012 International Conference, San Francisco, CA, May 18-23, 2012. Am J Respir Crit Care Med. 2012;185: A3136.

14. Dai B, Kang J, Sun LF, Tan W, and Zhao HW: Influence of exhalation valve and nebulizer position on albuterol delivery during noninvasive positive pressure ventilation. J Aerosol Med Pulm Drug Deliv. 2014;27:125-132.

15. Dhand R: Aerosol therapy in patients receiving noninvasive positive pressure ventilation. J Aerosol Med Pulm Drug Deliv. 2012;25:63-78.

16. Calvert LD, Jackson JM, White JA, Barry PW, Kinnear WJ, and O'Callaghan C: Enhanced delivery of nebulised salbutamol during non-invasive ventilation. J Pharm Pharmacol. 2006;58:1553-1557.

17. Chatmongkolchart S, Schettino GP, Dillman C, Kacmarek RM, and Hess DR: In vitro evaluation of aerosol bronchodilator delivery during noninvasive positive pressure ventilation: Effect of ventilator settings and nebulizer position. Crit Care Med. 2002;30:2515-2519.
18. Michotte JB, Jossen E, Roeseler J, Liistro G, and Reychler G: In vitro comparison of five nebulizers during noninvasive ventilation: Analysis of inhaled and lost doses. J Aerosol Med Pulm Drug Deliv. 2014;27:430-440.

19. Prince IR, Rabbetts I, and Denyer J: In vitro assessment of continuous, breath-actuated and Adaptive Aerosol Delivery $(A A D \circledR)$ for the delivery of aerosol into noninvasive ventilation. J Aerosol Med. 2007;20:365-392.

20. Hess DR: The mask for noninvasive ventilation: Principles of design and effects on aerosol delivery. J Aerosol Med. 2007;20 Suppl 1:S85-S98; discussion S98-S89.

21. Michotte JB, Staderini E, Le Pennec D, Dugernier J, Rusu R, Roeseler J, Vecellio L, Liistro G, and Reychler G: In vitro comparison of a vibrating mesh nebulizer operating in inspiratory synchronized and continuous nebulization modes during noninvasive ventilation. J Aerosol Med Pulm Drug Deliv. 2016;29:328-336.

22. Newman SP: How well do in vitro particle size measurements predict drug delivery in vivo? $\mathrm{J}$ Aerosol Med. 1998;11 Suppl 1:S97-S104.

23. Ari A, and Fink JB: Factors affecting bronchodilator delivery in mechanically ventilated adults. Nurs Crit Care. 2010;15:192-203.

24. Ari A, Fink JB, and Dhand R: Inhalation therapy in patients receiving mechanical ventilation: An update. J Aerosol Med Pulm Drug Deliv. 2012;25:319-332.

25. Branconnier MP, and Hess DR: Albuterol delivery during noninvasive ventilation. Respir Care. 2005;50:1649-1653.

26. Dequin PF, Faurisson F, Lemarie E, Delatour F, Marchand S, Valat C, Boissinot E, de Gialluly C, and Diot P: Urinary excretion reflects lung deposition of aminoglycoside aerosols in cystic fibrosis. Eur Respir J. 2001;18:316-322.

27. Reychler G, Leal T, Roeseler J, Thys F, Delvau N, and Liistro G: Effect of continuous positive airway pressure combined to nebulization on lung deposition measured by urinary excretion of amikacin. Respir Med. 2007;101:20512055.

28. Moraine JJ, Truflandier K, Vandenbergen N, Berre J, Melot $\mathrm{C}$, and Vincent JL: Placement of the nebulizer before the humidifier during mechanical ventilation: Effect on aerosol delivery. Heart Lung. 2009;38:435-439.

29. Abdelrahim ME, Plant PK, and Chrystyn $H$ : The relative lung and systemic bioavailability of terbutaline following nebulisation in non-invasively ventilated patients. Int J Pharm. 2011;420:313-318.

30. Ehrmann S, Mercier E, Vecellio L, Ternant D, Paintaud G, and Dequin PF: Pharmacokinetics of high-dose nebulized amikacin in mechanically ventilated healthy subjects. Intensive Care Med. 2008;34:755-762.

31. Marik P, Hogan J, and Krikorian J: A comparison of bronchodilator therapy delivered by nebulization and metered-dose inhaler in mechanically ventilated patients. Chest. 1999;115:1653-1657.

32. Miller MR, Hankinson J, Brusasco V, Burgos F, Casaburi $\mathrm{R}$, Coates A, Crapo R, Enright P, van der Grinten CP, Gustafsson P, Jensen R, Johnson DC, MacIntyre N, McKay R, Navajas D, Pedersen OF, Pellegrino R, Viegi G, Wanger $\mathrm{J}$, and Force AET: Standardisation of spirometry. Eur Respir J. 2005;26:319-338.

33. Franca EE, Dornelas de Andrade AF, Cabral G, Almeida Filho P, Silva KC, Galindo Filho VC, Marinho PE, Lemos A, and Parreira VF: Nebulization associated with bi-level noninvasive ventilation: Analysis of pulmonary radioaerosol deposition. Respir Med. 2006;100:721-728. 
34. Reychler G, Keyeux A, Cremers C, Veriter C, Rodenstein DO, and Liistro G: Comparison of lung deposition in two types of nebulization: Intrapulmonary percussive ventilation vs jet nebulization. Chest. 2004;125:502-508.

35. Xi J, Si X, Zhou Y, Kim J, and Berlinski A: Growth of nasal and laryngeal airways in children: Implications in breathing and inhaled aerosol dynamics. Respir Care. 2014;59:263-273.

36. Neale MG, Brown K, Hodder RW, and Auty RM: The pharmacokinetics of sodium cromoglycate in man after intravenous and inhalation administration. Br J Clin Pharmacol. 1986;22:373-382.

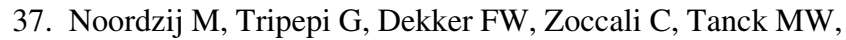
and Jager KJ: Sample size calculations: Basic principles and common pitfalls. Nephrol Dial Transplant. 2010;25: 1388-1393.

38. Bassetti M, Luyt CE, Nicolau DP, and Pugin J: Characteristics of an ideal nebulized antibiotic for the treatment of pneumonia in the intubated patient. Ann Intensive Care. 2016;6:35.

39. Miller DD, Amin MM, Palmer LB, Shah AR, and Smaldone GC: Aerosol delivery and modern mechanical ventilation: In vitro/in vivo evaluation. Am J Respir Crit Care Med. 2003;168:1205-1209.

40. Ghazanfari T, Elhissi AM, Ding Z, and Taylor KM: The influence of fluid physicochemical properties on vibratingmesh nebulization. Int J Pharm. 2007;339:103-111.

41. MacLoughlin RJ, Higgins BD, Laffey JG, and O'Brien T: Optimized aerosol delivery to a mechanically ventilated rodent. J Aerosol Med Pulm Drug Deliv. 2009;22:323-332.

42. Lin HL, Wan GH, Chen YH, Fink JB, Liu WQ, and Liu $\mathrm{KY}$ : Influence of nebulizer type with different pediatric aerosol masks on drug deposition in a model of a spontaneously breathing small child. Respir Care. 2012;57:1894-1900.

43. Reychler G, Aubriot AS, Depoortere V, Jamar F, and Liistro G: Effect of drug targeting nebulization on lung deposition: A randomized crossover scintigraphic comparison between central and peripheral delivery. Respir Care. 2014;59:1501-1507.

44. Ehrmann S, Lyazidi A, Louis B, Isabey D, Le Pennec D, Brochard L, and Apiou-Sbirlea G: Ventilator-integrated jet nebulization systems: Tidal volume control and efficiency of synchronization. Respir Care. 2014;59:1508-1516.

45. Longest PW, Azimi M, and Hindle M: Optimal delivery of aerosols to infants during mechanical ventilation. J Aerosol Med Pulm Drug Deliv. 2014;27:371-385.

46. Lin HL, Fink JB, Zhou Y, and Cheng YS: Influence of moisture accumulation in inline spacer on delivery of aerosol using metered-dose inhaler during mechanical ventilation. Respir Care. 2009;54:1336-1341.

47. Walenga RL, Tian G, Hindle M, Yelverton J, Dodson K, and Longest PW: Variability in nose-to-lung aerosol delivery. J Aerosol Sci. 2014;78:11-29.

48. Fink J, and Ari A: Aerosol delivery to intubated patients. Expert Opin Drug Deliv. 2013;10:1077-1093.

49. Beringer PM, Owens H, Nguyen A, Benitez D, Rao A, and D'Argenio DZ: Pharmacokinetics of doxycycline in adults with cystic fibrosis. Antimicrob Agents Chemother. 2012; 56:70-74.

50. Pelkonen AS, Nikander K, and Turpeinen M: Jet nebulization of budesonide suspension into a neonatal ventilator circuit: Synchronized versus continuous nebulizer flow. Pediatr Pulmonol. 1997;24:282-286.

51. Wan GH, Lin HL, Fink JB, Chen YH, Wang WJ, Chiu YC, Kao YY, and Liu CJ: In vitro evaluation of aerosol delivery by different nebulization modes in pediatric and adult mechanical ventilators. Respir Care. 2014;59:1494-1500.

52. Duarte AG: Inhaled bronchodilator administration during mechanical ventilation. Respir Care. 2004;49:623-634.

53. Manthous CA, Hall JB, Schmidt GA, and Wood LD: Metereddose inhaler versus nebulized albuterol in mechanically ventilated patients. Am Rev Respir Dis. 1993;148:1567-1570.

54. Bennett WD, Zeman KL, and Kim C: Variability of fine particle deposition in healthy adults: Effect of age and gender. Am J Respir Crit Care Med. 1996;153:1641-1647.

55. Ferron GA: Aerosol properties and lung deposition. Eur Respir J. 1994;7:1392-1394.

56. Dhand R: Aerosol delivery during mechanical ventilation: From basic techniques to new devices. J Aerosol Med Pulm Drug Deliv. 2008;21:45-60.

57. Dhand R, and Mercier E: Effective inhaled drug administration to mechanically ventilated patients. Expert Opin Drug Deliv. 2007;4:47-61.

58. Branson RD, and Gentile MA: Is humidification always necessary during noninvasive ventilation in the hospital? Respir Care. 2010;55:209-216; discussion 216.

59. Hill NS: Noninvasive ventilation for chronic obstructive pulmonary disease. Respiratory Care. 2004;49:72-87; discussion 87-79.

60. Hess D, Fisher D, Williams P, Pooler S, and Kacmarek RM: Medication nebulizer performance. Effects of diluent volume, nebulizer flow, and nebulizer brand. Chest. 1996; 110:498-505.

61. Gowda AA, Cuccia AD, and Smaldone GC: Reliability of vibrating mesh technology. Respir Care. 2017;62:65-69.

62. Romeo VD, deMeireles J, Sileno AP, Pimplaskar HK, and Behl CR: Effects of physicochemical properties and other factors on systemic nasal drug delivery. Adv Drug Deliv Rev. 1998;29:89-116.

63. O'Hagan DT, Critchley H, Farraj NF, Fisher AN, Johansen BR, Davis SS, and Illum L: Nasal absorption enhancers for biosynthetic human growth hormone in rats. Pharm Res. 1990;7:772-776.

64. Agu RU, Jorissen M, Willems T, Van den Mooter G, Kinget $\mathrm{R}$, and Augustijns P: Effects of pharmaceutical compounds on ciliary beating in human nasal epithelial cells: A comparative study of cell culture models. Pharm Res. 1999;16:1380-1385.

65. Merkus FW, Verhoef JC, Schipper NG, and Marttin E: Nasal mucociliary clearance as a factor in nasal drug delivery. Adv Drug Deliv Rev. 1998;29:13-38.

66. Passali D, and Bianchini Ciampoli M: Normal values of mucociliary transport time in young subjects. Int J Pediatr Otorhinolaryngol. 1985;9:151-156.

Received on August 9, 2016 in final form, May 25, 2017

Reviewed by: Armele Dornelas Laurent Vecellio

Address correspondence to: Jean-Bernard Michotte, PT, PhD Filière Physiothérapie

Haute Ecole de Santé Vaud Avenue de Beaumont, 21 1011 Lausanne Switzerland

E-mail: jean-bernard.michotte@hesav.ch 